\title{
$\beta$-blockers: a novel class of antitumor agents
}

This article was published in the following Dove Press journal:

OncoTargets and Therapy

23 November 2012

Number of times this article has been viewed

Yi Jil,*

Siyuan Chen ${ }^{2, *}$

Xianmin Xiao'

Shan Zheng'

Kai Li'

'Division of Oncology, Department of Pediatric Surgery, ${ }^{2}$ Research Institute of Pediatrics, Children's Hospital of Fudan University, Shanghai, China

*These authors contributed equally to this work
Correspondence: Kai Li

Division of Oncology, Department of Pediatric Surgery, Children's Hospital of Fudan University, 399 Wanyuan Road, 201102, Shanghai, China

Tel +862 2। $6493 \quad$ I2I 2

Fax +86 2I 6493 |2।I

Email likai2727@I63.com
Abstract: $\beta$-adrenergic signaling modulates key signaling pathways that are important for tumorpromoting processes, and numerous mechanisms of action have been elucidated. Preclinical studies have demonstrated that $\beta$-adrenergic antagonists, or $\beta$-blockers, can block multiple fundamental biologic processes underlying the progression and metastasis of tumors, including the inhibition of cell proliferation, migration, invasion, resistance to programmed cell death, and tumor angiogenesis and metastasis. Human pharmacoepidemiologic studies suggest that $\beta$-blockers have a role in inhibiting cancer progression and metastasis in combination with standard therapies. Furthermore, a number of prospective studies have demonstrated that $\beta$-blockers are effective at halting infantile hemangioma growth. These findings shed light on the novel perspective of using $\beta$-blockers as a class of potential antitumor agents in clinical oncology.

Keywords: $\beta$-adrenergic signaling, cancer, $\beta$-blockers, progression, metastasis, angiogenesis

\section{Introduction}

$\beta$-blockers are a class of drugs used for various indications, particularly for the management of cardiac arrhythmia, cardioprotection after myocardial infarction, hypertension, migraines, and tremors. The therapeutic activity of $\beta$-blockers is attributed to the blockade of $\beta_{1}$-adrenergic receptors (ARs), which are predominantly expressed in cardiac tissue. $\beta_{2}$-AR is expressed in the bronchiolar smooth muscle of the lung and other tissues and resembles $\beta_{1}$-AR in its molecular and pharmacological properties. Accordingly, $\beta$-blockers can be classified by cardioselectivity and intrinsic sympathomimetic activity. Cardioselective $\beta$-blockers preferentially inhibit $\beta_{1}$ receptors. Noncardioselective $\beta$-blockers inhibit both $\beta_{1}$ - and $\beta_{2}$-AR sites (Table 1). ${ }^{1}$ Propranolol was the first clinically useful $\beta$-AR blocker and is nonselective for the $\beta_{1}$ - and $\beta_{2}$-ARs. Invented by Sir James W Black, propranolol revolutionized the medical management of angina pectoris, and this drug is considered to be one of the most important contributions to clinical medicine and pharmacology of the 20th century.,

The $\beta$-ARs, a family of G-protein-coupled receptors that are activated by $\beta$-adrenergic agonists, can initiate a series of signaling cascades, thereby leading to multiple, cellspecific responses. There is evidence suggesting that $\beta$-adrenergic signaling plays a role in basic developmental processes (eg, embryogenesis and morphogenesis), including the control of cell proliferation, differentiation and migration. ${ }^{46}$ Furthermore, $\beta$-adrenergic signaling has been found to regulate multiple biological processes that contribute to the initiation and progression of cancer. Based on this connection, emerging evidence suggests that $\beta$-blockers, either in vitro or in vivo, significantly reduce the proliferation, angiogenesis and metastasis of the most common human malignancies, including 
Table I Classes of $\beta$-blockers

\begin{tabular}{ll}
\hline Class & Drugs \\
\hline Cardioselective $\beta$-blocker & Alprenolol, oxprenolol, \\
& propranolol, penbutolol, pindolol, \\
& bopindolol, nadolol, sotalol, timolol \\
Noncardioselective $\beta$-blocker & Acebutolol, bisoprolol, betaxolol, \\
& practolol, atenolol, metoprolol \\
\hline
\end{tabular}

adenocarcinoma of the breast, ${ }^{7,8}$ lung, ${ }^{9}$ pancreas, ${ }^{10-12}$ prostate, ${ }^{13}$ colon, ${ }^{14}$ and stomach, ${ }^{15}$ as well as in ovarian cancer. ${ }^{16}$ This finding has led to the hypothesis that commonly prescribed $\beta$-blockers may favorably impact cancer progression and metastasis in patients. In fact, the recent encouraging results from studies using $\beta$-blockers ${ }^{4-6}$ as a class of antitumor agents have been discovered as a result of decades of meticulous groundwork, followed by a few key observations in patients being treated with $\beta$-blockers in clinical trials. In this review, we will discuss the function of $\beta$-blockers, their antitumor activity in animal models and cell lines, and their potential as a novel tumor therapy.

\section{Laboratory science}

\section{$\beta$-adrenergic signaling modulates multiple cellular processes}

The neurotransmitters epinephrine and norepinephrine are the physiological agonists for $\beta$-ARs. These two neurotransmitters are catecholamines that are not only released from the adrenal medulla as a response to psychological and physical stress, but they also regulate cell and organ responses to the sympathetic branch of the autonomic nervous system. The synthesis and release of epinephrine and norepinephrine are regulated by nicotinic acetylcholine receptors (nAChRs). ${ }^{17}$ Ligation of $\beta$-ARs by epinephrine or norepinephrine triggers a G-protein-coupled signaling cascade that stimulates cyclic adenosine monophosphate (cAMP) synthesis. This second messenger, cAMP, regulates many cellular functions through its effectors, such as cAMPdependent protein kinase (PKA) and exchange proteins directly activated by cAMP (EPAC). ${ }^{18,19}$ PKA regulates a wide variety of cellular processes ranging from general metabolism and growth to cell-specific processes, such as differentiation, morphology, motility, secretion, neurotransmission, and gene transcription. ${ }^{20}$ EPAC signaling accounts for many cAMP-induced effects on cell morphology, motility, and secretion dynamics. ${ }^{21,22}$

\section{Blockade of $\beta$-ARs reduce tumor progression and metastasis}

The possible causes and mechanisms of tumorigenesis have provoked much debate and controversy. However, out of this tumult has emerged the widely accepted principle that both the process of carcinogenesis and the resulting tumors are extremely complex. Preclinical studies have demonstrated that $\beta$-adrenergic signaling can regulate multiple fundamental biologic processes underlying the progression and metastasis of tumors, including promotion of inflammation, ${ }^{23-25}$ angiogenesis, ${ }^{26,27}$ migration, ${ }^{28}$ invasion, ${ }^{29}$ and resistance to programmed cell death. ${ }^{30,31}$ Some evidence suggests that the stimulation of $\beta$-adrenergic signaling can also inhibit DNA damage repair ${ }^{32,33}$ and cellular immune response, ${ }^{34,35}$ and promote surgery-induced metastasis. ${ }^{16,36,37}$ Because $\beta$-adrenergic signaling can modulate multiple biologic processes and pathways underlying tumor progression and metastasis, $\beta$-blockers may be highly desirable for therapeutic intervention. Although the antitumor mechanisms of $\beta$-blockers are described separately below, there are numerous interactions among them, which indirectly reflect the complexity of tumor pathogenesis.

\section{Angiogenesis}

Angiogenesis is critical for tumor growth and progression. The neovessels of tumors are mainly formed from preexisting vessels via the proliferation and migration of endothelial cells together with the contribution of endothelial progenitor cells and endothelial stem cells. ${ }^{38,39}$ It is now well established that the overexpression of vascular endothelial growth factor (VEGF), a key proangiogenic protein, is associated with progression in several tumor types, including prostate cancer, ${ }^{40}$ breast cancer, ${ }^{41}$ hepatocellular carcinoma, ${ }^{42}$ and infantile hemangioma $(\mathrm{IH}){ }^{43}$ The $\beta$-ARs are important for mediating the production of this key proangiogenic cytokine. Exposure to a chronic stressor promoted in vivo angiogenesis and the production of VEGF. This effect was eliminated by silencing tumor cell $\beta$-AR expression, implicating tumor cell $\beta$-AR expression and signaling as important facilitators of stressinduced tumor angiogenesis in vivo. ${ }^{27}$

In vitro studies using tumor cell lines suggest that catecholamines can promote tumor progression via a $\beta$-ARdriven, proangiogenic pathway. The stimulation of VEGF expression by $\beta$-adrenergic signaling is proportional to $\beta$-AR expression and is dose-dependent. ${ }^{44}$ Conversely, $\beta$-blockers such as propranolol lead to the reduced expression of VEGF and thus to inhibition of angiogenesis (Figure 1). Furthermore, the impairment of signal transduction at the $\beta_{2}$-AR level in vascular endothelial cells can directly result in impairment to angiogenesis in vivo and tubulogenesis in vitro. ${ }^{45,46}$ It has been suggested that the benefits observed during $\mathrm{IH}$ treatment are also primarily due to the inhibition of VEGF 


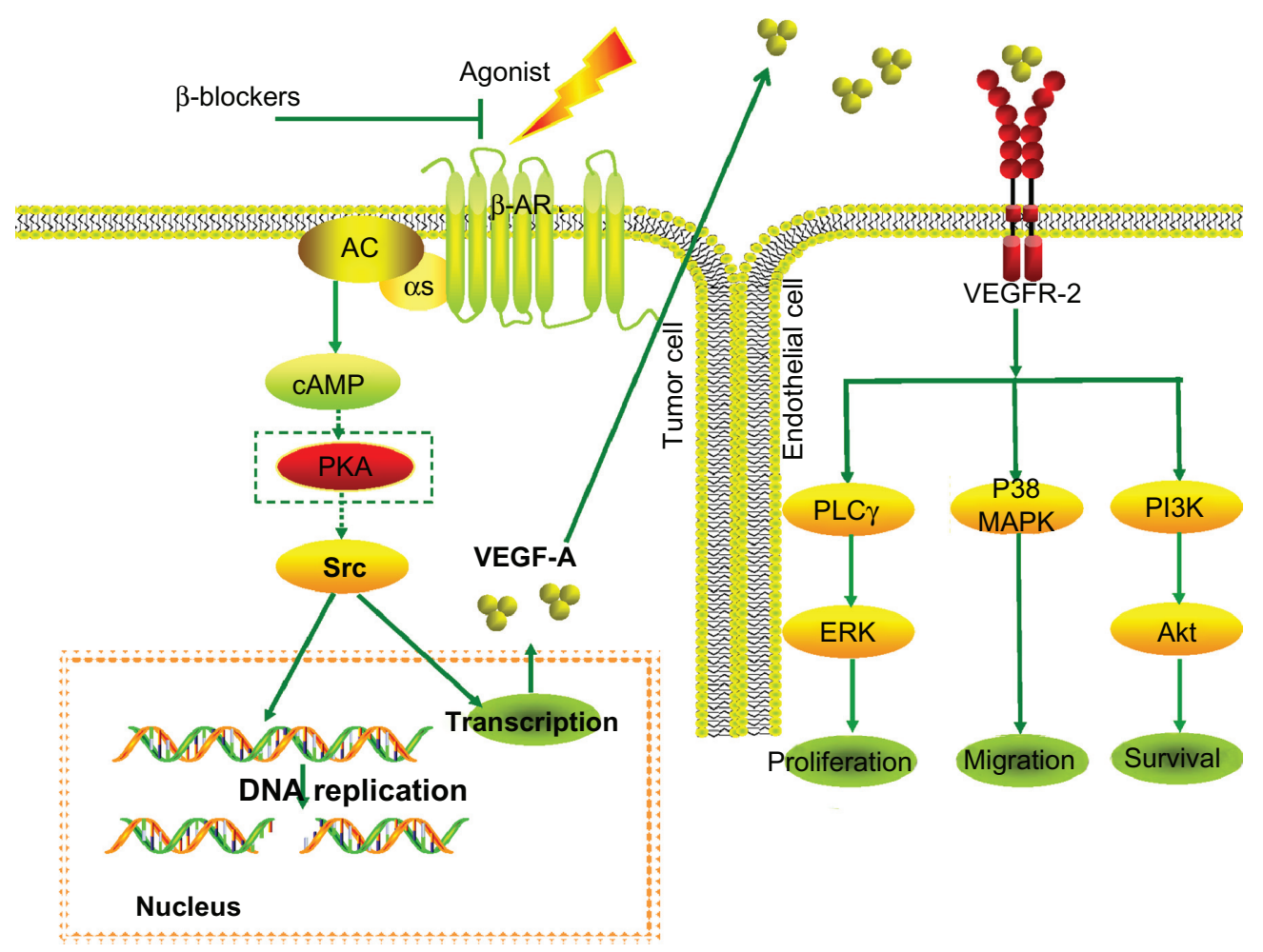

Figure I $\beta$-blockers abolish induction of VEGF expression by $\beta$-adrenergic agonists, leading to inhibition of angiogenesis.

Notes: The neurotransmitters epinephrine and norepinephrine bind to $\beta$-ARs, resulting in $\mathrm{G}_{\alpha s}$-mediated activation of adenylyl cyclase and subsequent cAMP synthesis. One cAMP effector involves activation of PKA which belongs to a family of cytoplasmic tyrosine kinases involved in the control of diverse cellular processes. For example, exposure to a chronic stressor promoted production of VEGF. VEGF is a proangiogenic molecule that stimulates endothelial cell proliferation and migration, and promotes endothelial cell survival. Conversely, $\beta$-blockers lead to a reduced expression of VEGF and thus to an inhibition of angiogenesis.

Abbreviations: ARs, adrenergic receptors; cAMP, cyclic AMP; ERK, extracellular signal-regulated kinase; PI3K, phosphatidylinositol-3-kinase; PKA, cAMP-dependent protein kinase; PLC $\gamma$, phospholipase C- $\gamma$; MAPK, mitogen-activated protein kinase; VEGF, vascular endothelial growth factor.

production by propranolol..$^{47,48}$ This suggestion has recently been confirmed by Chim et al, ${ }^{49}$ who demonstrated that propranolol exerts its suppressive effects on hemangiomas through the hypoxia inducible factor (HIF)-1 $\alpha$-VEGF-A angiogenesis axis, the effects of which are mediated through the PI3/Akt and p38/MAPK pathways.

\section{Cell proliferation}

Controlling cellular proliferation in tumors may be an effective treatment strategy. The stimulation of $\beta$-AR by lifestyle and environmental factors, as well as a preexisting risk for neoplasm, can activate downstream effector molecules and encourage cancer growth by promoting cell proliferation. ${ }^{50,51}$ The first evidence for a regulatory role of $\beta$-adrenergic signaling in cancer cells was provided by Schuller and Cole. ${ }^{52}$ These researchers demonstrated a significant increase in the proliferation of lung adenocarcinoma cells in response to the $\beta$-AR agonist isoproterenol, with propranolol inhibiting the proliferation response. After this report, a number of studies have demonstrated that the epinephrine and norepinephrine neurotransmitters can induce cell proliferation in different cancer types. ${ }^{9,24,53}$ These effects are mediated primarily through
$\beta_{2}$-AR activation in the cAMP-PKA signaling pathway in tumor cells. ${ }^{54}$ However, there is evidence suggesting that epinephrine can directly stimulate esophageal cancer cell proliferation via the $\beta_{1} / \beta_{2}$-AR/ERK/COX-2 pathway and the $\beta_{1}$-AR-dependent upregulation of cyclins and cyclindependent kinases. ${ }^{55}$ Interestingly, inhibition of cell proliferation has also been described by agonists in breast cancer cells. ${ }^{56}$ Moreover, the study by Carie and Sebti showed in vitro and in vivo a clear reduction of cell proliferation and tumor growth by a $\beta$-adrenergic agonist in breast and other cancers. ${ }^{57}$

It is well known that nicotine can stimulate tumor growth and angiogenesis; however, nicotine itself does not cause neoplastic transformation. ${ }^{17}$ Several studies have shown that nicotine-derived nitrosamine (4)-methylnitrosamino-1-(3pyridl)-1-butanone (NNK) is a high-affinity agonist for both $\beta$-ARs and nAChRs. ${ }^{58,59} \mathrm{NNK}$ can induce the development of pulmonary adenocarcinoma (PAC) in vivo, thereby indicating a direct and causative association between smoking and the incidence of PAC. ${ }^{60}$ Subsequent investigations revealed that NNK stimulated the proliferation of PAC cells via a cAMPdependent signaling cascade that includes the activation of the transcription factor cAMP response-element binding protein 
(CREB), the PKA-dependent epidermal growth factor receptor (EGFR) pathway, and the $\beta$-AR-mediated release of arachidonic acid. ${ }^{58,61,62}$ Moreover, endogenous physiological epinephrine significantly increased NNK-induced cell proliferation. In contrast to these observed agonistic effects, propranolol completely abrogated NNK-induced proliferation. ${ }^{63,64}$

\section{Apoptosis}

Apoptosis is a form of cell death with features that are distinct from those of necrosis. It has become increasingly clear that the apoptotic cell death process is a relatively ubiquitous phenomenon that is observed in numerous cancer tissues and cell lines. There is evidence suggesting that $\beta$-AR may trigger multiple signaling pathways that could contribute to the induction of apoptosis, including the down-regulation of antiapoptotic proteins/genes and the activation of the caspase cascade. ${ }^{51,65,66}$ Because resistance to apoptosis has been implicated in cancer pathogenesis, a number of studies have sought to analyze the effects of $\beta$-adrenergic signaling on apoptosis during tumor progression. In a study by Sastry et al, ${ }^{67}$ the authors demonstrated that epinephrine reduces the sensitivity to apoptosis of both prostate cancer and breast cancer cells via $\beta$-AR/PKA signaling, which triggers BAD phosphorylation at $\mathrm{S} 112$, an effect that was completely reversed using a $\beta_{2}$-AR-specific antagonist. Analogous to these findings, other studies determined that the inhibition of $\beta$-AR signaling using propranolol or a $\beta_{2}$-AR antagonist in combination with gemcitabine induces apoptosis in pancreatic cancer cells ${ }^{68,69}$ Furthermore, it was demonstrated that $\beta$-adrenergic inhibition by propranolol can enhance the effect of radiotherapy on gastric cancer cells in vitro through the induction of apoptosis via NF $\kappa$ B downregulation. ${ }^{70}$

Resistance to anoikis is a hallmark of malignant transformation. Anoikis provides tumor cells with increased survival times in the absence of matrix attachment and facilitation migration, reattachment, and colonization of secondary sites. ${ }^{71}$ Analysis of cellular models and an orthotopic mouse model of human ovarian cancer demonstrated that catecholamines can protect ovarian cancer cells from anoikis and that these effects are mediated by focal adhesion kinase (FAK) phosphorylation through the $\beta_{2}$-AR-dependent activation of Src. Furthermore, all of these effects were blocked by propranolol or the $\beta_{2}$-AR-specific antagonist butoxamine. ${ }^{72}$ Additional studies using human clinical tumors showed that both depression and tumor norepinephrine content were associated with increased FAK activation and that increased FAK activation was associated with substantially accelerated disease progression. ${ }^{72}$

\section{Inflammation}

Researchers estimate that inflammation may contribute to the development of up to $15 \%$ of all cancers. ${ }^{73}$ It has been demonstrated that pro-inflammatory cytokines might promote tumorigenesis by inducing DNA damage or inhibiting DNA repair through the generation of reactive oxygen species. ${ }^{35}$ Pro-inflammatory cytokines can also lead to the inactivation of tumor suppressor genes, the promotion of autocrine or paracrine growth, the survival of tumor cells, the stimulation of angiogenesis, or the subversion of the immune response..$^{35,73}$ Among the pro-inflammatory cytokines displaying the striking effects was interleukin 6 (IL-6). IL-6 has been shown to participate in the epithelial-mesenchymal transition of human breast cancer cells. ${ }^{74}$ IL- 6 has also been shown to be secreted by ovarian cancer cells and to facilitate tumor cell proliferation, migration, and chemotherapy resistance. ${ }^{75}$ In addition, IL-6 is a potent angiogenic cytokine in vivo. ${ }^{76,77}$

Elevated levels of IL-6 are frequently detected in the serum of breast cancer and ovarian cancer patients and are associated with poor prognosis and increased tumor burden. More importantly, both physical and psychological stressors can provoke transient, increased levels of pro-inflammatory cytokines. $\beta$-AR-induced IL- 6 production has been observed in a variety of normal cell types ${ }^{78}$ and tumor cell types, ${ }^{79}$ even in the absence of a pro-inflammatory stimulus. ${ }^{80}$ There is evidence suggesting that chronic stress hormones affect IL-6 expression in breast and ovarian cancer through $\beta$-adrenergic signaling and contribute to angiogenesis in these tumors. Conversely, $\beta$-blockers such as propranolol have been shown to block many of the deleterious effects of stress. ${ }^{81,82}$ Another example involves chronic stress linked to IL-8, which is highly expressed in the majority of human cancers and has also been identified as a driver of tumor progression in various cancer types. ${ }^{83,84}$ It has been demonstrated that epinephrine and norepinephrine can enhance IL-8 expression through $\beta_{2}$-AR and thereby mediate the effects of stress on the growth and metastasis of ovarian cancer; notably, these effects are all blocked by propranolol. ${ }^{23}$

\section{Immune response}

Evidence from cancer patients clearly indicates that the immune system extensively interacts with developing primary tumors, metastasizing cells, and established metastases, and that the immune system can recognize and kill many malignant cells. ${ }^{85} \beta$-adrenergic signaling plays an important role in the regulation of tumor-directed immune responses. Both tumor-bearing animals and cancer patients have disrupted endocrine and immunological cycles, with 
greater disruption observed in cases where the tumor is advanced or fast-growing. ${ }^{35,86}$ Emerging evidence suggests that stress hormone catecholamines have specific effects on the immune systems of cancer patients. These effects include reducing lymphocyte proliferation, ${ }^{87,88}$ decreasing natural killer (NK) cell cytotoxicity, ${ }^{35,86}$ and reducing T-cell response to mitogen stimulation. ${ }^{89}$ Catecholamines can also activate oncogenic viruses and alter antibody production, cytokine production profiles, and cell trafficking. ${ }^{34}$ Most importantly, catecholamine can increase the prometastatic effects of the tumor immune response. Many tumors release catecholamines or recruit tumor-associated macrophages to do so, presumably as an immune-escape mechanism or to promote tumor vascularization. ${ }^{7,90}$

\section{Migration and invasion}

Activating the migratory ability of tumor cells is a prerequisite for tumor cell invasion and metastasis. There is evidence to suggest that tumor cell migration can be activated by signal substances from the neuroendocrine system. In vivo cancer models have shown that norepinephrine exerts both chemokinetic and chemoattractive effects on colon, ${ }^{91}$ prostate, ${ }^{92}$ and breast cancer cells. ${ }^{93}$ By contrast, the norepinephrine-induced stimulation of cancer cell migration can be inhibited by propranolol or $\gamma$-aminobutyric acid (GABA)-mediated reduction of cAMP-dependent signaling. ${ }^{94}$

Tumor cell invasion is a key step in the pathogenesis of metastasis. Matrix metalloproteinases (MMP) play a critical role in cell invasion by degrading components of the extracellular matrix. Indirect evidence suggests that catecholamines could potentially enhance tumor cell invasiveness because norepinephrine has been shown to affect tumor cell motility in vivo and because circulating catecholamines have been associated with the in vivo expression of MMPs that facilitate invasion. ${ }^{91,94-97}$ Sood et $\mathrm{al}^{29}$ established that physiologically relevant concentrations of norepinephrine and epinephrine can significantly enhance the capacity of ovarian tumor cells to invade the extracellular matrix via the $\beta$-adrenergic upregulation of MMP-2 and MMP-9. Additional findings by the same research group reported that the effects of norepinephrine and epinephrine are dependent on the activation of signal transducer and activator of transcription-3 (STAT-3) and proceeding through the $\beta 1 / \beta 2-\mathrm{AR}$ and PKA. ${ }^{98}$ Similarly, Yang et $\mathrm{al}^{99}$ and Guo et al ${ }^{100}$ determined that exposing nasopharyngeal carcinoma tumor cells and pancreatic cancer cells to norepinephrine resulted in increased production of the MMPs responsible for invasion responses; notably, these effects were completely blocked by propranolol.

\section{Metastasis}

Metastasis is the most common cause of morbidity and mortality in solid cancer patients. Psychosocial and physical stressors have been ascribed with playing a role in the incidence and metastasis of cancer. ${ }^{97}$ Experimental stressors have been found to increase metastasis in various animal tumor models. There is evidence to suggest that social stress in mice increases the metastasis rates of breast cancer xenografts, ${ }^{7}$ and that stress induced by passive restraint as well as treatment with epinephrine had similar effects on ovarian cancer metastasis. ${ }^{29}$ Recent studies clearly indicate that physiological levels of catecholamines, or the release of these compounds after surgery, result in increased breast ${ }^{36}$ and ovarian ${ }^{16}$ carcinoma lymph node and lung metastases. Previously, the immune system had been attributed with functioning as a mediator between malignant tumors and the neuroendocrine system, and, as a consequence of this mediating role, immune suppression was hypothesized to enhance tumor establishment. Indeed, it has been demonstrated that the cytotoxicity of NK cells is strongly impaired by catecholamines, which might be supportive for the effects of metastasis formation. ${ }^{35,86}$ It has also been shown that chronic stress hormones can regulate breast cancer progression and metastasis by recruiting or modifying the activity of tumor-associated macrophages and the associated intratumoral expression of pro-metastatic genes, including VEGF, MMP-9, COX-2, transforming growth factor (TGF)- $\beta$ and serum arginase (ARG)-1, as well as progression-inhibitory genes such as interferon (IFN)- $\beta$. ${ }^{\text {? }}$

In addition to the role of the immune system at mediating stress effects on tumor growth and metastasis, there are now many reports indicating that chronic stress hormones can act directly by stimulating the pro-metastatic capacities of the malignant tissue and its microenvironment. These effects were mediated primarily through the activation of the tumor cell cAMP/PKA signaling pathway by $\beta_{2}-\mathrm{AR} .^{27,99,101,102}$ Conversely, treatment with propranolol significantly reduces these effects. Interestingly, using the BALB/c nude mice model, Palm et $\mathrm{al}^{13}$ observed that $\beta$-AR activation by norepinephrine had no effect on the growth of primary prostate cancer; however, there was an increase in the rate and magnitude of distant metastasis. In the study by Sloan et al, ${ }^{7}$ stress-induced neuroendocrine activation actually had a negligible impact on primary tumor growth; however, this activation induced a 30 -fold increase in metastasis to distant tissues. Similarly, pharmacological activation of $\beta$-adrenergic signaling by isoproterenol induced the same effects (ie, an increase in the number and mass of distant metastases by 
nearly 22-fold without substantially impacting primary tumor growth). ${ }^{7}$ Perhaps most importantly, pretreating the animals with $\beta$-blockers synergistically blocked the effects of behavioral stress and/or $\beta$-adrenergic signaling activation on tumor metastasis. However, $\beta$-blockers have little effect on primary tumor growth. ${ }^{7,13}$ These findings lead to a conceptual change concerning the therapeutic role for $\beta$-blockers: $\beta$-blockers may protect against cancer progression and metastasis in already established cancers rather than preventing primary cancer occurrence or its cure. ${ }^{103}$ These findings also suggest that clinically testing the use of $\beta$-blockers as an adjuvant therapy for the chemoprevention of metastasis development in cancer patients should be performed, especially with regard to the fact that the diagnosis of cancer itself and the according clinical treatment causes stress (eg, surgical stress).

\section{Epidemiological and clinical studies Do $\beta$-blockers influence cancer incidence?}

As previously stated, multiple lines of evidence indicate that an elevated level of catecholamine stress neurotransmitters may be an etiological factor in various types of cancer. This hypothesis is immediately and, to some degree, directly testable by the epidemiological analysis of the medical records from people who have taken anti-catecholamine drugs such as $\beta$-blockers. A number of retrospective population studies suggest that $\beta$-blockers may have a protective role in reducing the incidence of all cancer types. ${ }^{104-106}$ In addition, the hypothesis of a protective effect of $\beta$-blockers against specific types of cancer is supported by studies of prostate cancer ${ }^{107,108}$ and colorectal cancer. ${ }^{109}$ In contrast, several epidemiologic studies have identified a positive association between $\beta$-blockers and the risk of cancer. ${ }^{110,111}$ In a recent study by Jansen et al, ${ }^{111}$ information on $\beta$-blocker use and potential confounders was collected for colorectal cancer cases and controls. The study concluded that there was no association between colorectal cancer and the use of $\beta$-blockers or any subclass of $\beta$-blockers after adjusting for confounding factors. However, the study indicated a positive association between long-term $\beta$-blocker use and the risk of stage IV colorectal cancer.

Other studies have found no relationship between $\beta$-blocker use and the risk of cancer. ${ }^{109,112}$ Data from studies on melanoma did not reveal any impact of $\beta$-blocker use on melanoma incidence. ${ }^{113,114}$ In addition, several epidemiologic studies examining the effect of $\beta$-blocker intake on breast cancer incidence have consistently found no significant link. ${ }^{115,116}$ Hence, the relationship between the use of $\beta$-blockers and cancer remains controversial.
Recently, a meta-analysis using only randomized trials to minimize the effect of confounding factors was performed by Bangalore et al. ${ }^{117}$ In this study, the authors identified 70 randomized controlled trials (148 comparator groups) with 324,168 participants. Reassuringly, their results suggest no evidence of even a $5 \%-10 \%$ relative risk increase in cancer or cancer-related deaths for any individual class of antihypertensive drugs (eg, $\beta$-blockers) studied.

\section{Do $\beta$-blockers influence cancer progression?}

$\beta$-blockers reduce melanoma progression

Two retrospective studies, by De Giorgi et $\mathrm{al}^{113}$ and Lemeshow et al, ${ }^{114}$ examined the association between the exposure of melanoma patients to $\beta$-blocker medication and survival. In the study by De Giorgi et al, ${ }^{113} 30$ patients received $\beta$-blockers and were matched with 91 patients who were not treated. After adjusting for age and Breslow thickness, they concluded that $\beta$-blocker treatment was inversely associated with recurrence and that there was a significant reduction in the risk of relapse for each year of $\beta$-blocker use. The study by Lemeshow et $\mathrm{al}^{114}$ used the national tumor registry in Denmark and a publicly available pharmacy database of 4179 patients diagnosed with melanoma with a median follow-up of 4.9 years. The authors compared melanoma patients receiving $\beta$-blockers (including metoprolol, propranolol, and atenolol) either within 90 days of diagnosis or more than 90 days prior to diagnosis, who were matched with patients not receiving a $\beta$-blocker. There was a significant reduction in melanomarelated death and all-cause mortality for the $\beta$-blocker users. The improved overall survival of melanoma patients receiving $\beta$-blockers following their diagnosis suggests that these compounds might prevent metastatic disease progression.

\section{$\beta$-blockers reduce breast cancer metastasis, recurrence, and mortality}

A retrospective study by Powe et $\mathrm{al}^{118}$ reported on a study of 466 women with breast cancer who were treated for hypertension, with or without $\beta$-blocker medication. Women receiving $\beta$-blockers demonstrated a remarkable reduction in distant metastases and tumor recurrence and a $71 \%$ reduction in cancer-specific mortality. This was the first report in humans to suggest the protective effect of $\beta$-blockers in the treatment of breast cancer. In a subsequent study by Ganz et al, ${ }^{119}$ the authors used observational data from 1779 women from the Kaiser Permanente Northern California Cancer Registry to examine the association between $\beta$-blockers and breast cancer recurrence, breast cancer-specific mortality, 
and overall mortality. Compared to women not exposed to $\beta$-blockers, women taking $\beta$-blockers displayed a nonsignificant $14 \%$ reduction in the risk of breast cancer recurrence, a nonsignificant $24 \%$ reduction in the risk of breast cancerspecific mortality, and no reduction in all-cause mortality.

Population studies by Barron et $\mathrm{al}^{115}$ and Melhem-Bertrandt et al ${ }^{116}$ also suggest that $\beta$-blockers may provide therapeutic leverage in the context of breast cancer. In the study by Barron et al, ${ }^{115}$ the linked National Cancer Registry in Ireland and prescription dispensing data were used to identify women diagnosed with stages I to IV invasive breast cancer. The authors compared women taking either propranolol or atenolol during the year before their breast cancer diagnosis, and these women were matched (1:2) with women not taking $\beta$-blockers for age, socioeconomic factors, marital status, smoking status, tumor grade or size, chemotherapy, and use of long-term prophylactic medications (eg, statins or aspirin). The authors determined that propranolol users were significantly less likely to present with a T4, node-positive (N2/N3) or metastatic disease (M1) compared with the matched non- $\beta$-blocker users. Furthermore, a longer duration of propranolol use was associated with fewer T4 tumors, suggesting the possibility of a dose-dependent relationship. However, there was no significant difference in $\mathrm{T} 4$ or $\mathrm{N} 2 / \mathrm{N} 3 / \mathrm{M} 1$ tumor incidence and breast cancer-specific mortality between atenolol users and matched nonusers. In the study by Melhem-Bertrandt et al, ${ }^{116}$ the authors retrospectively reviewed 1414 patients with breast cancer who received neoadjuvant chemotherapy. Medication usage in this study was obtained through patient self-reporting, as recorded in the medical records, and then extracted into the clinical research database. The most commonly prescribed $\beta$-blockers were metoprolol (42\%) and atenolol (37\%). Melhem-Bertrandt et $\mathrm{al}^{116}$ compared the patients with and without $\beta$-blocker exposure for pathologic complete response (pCR), relapse-free survival (RFS), and overall survival. They found that $\mathrm{pCR}$ rates were not associated with $\beta$-blocker usage. However, $\beta$-blocker usage was associated with a significantly better RFS. Furthermore, $\beta$-blocker usage was associated with improved RFS among patients with triple-negative breast cancer. The clinical results from these reports strongly suggest that the effect of $\beta$-blockers on the treatment of breast cancer is dependent on protecting against cancer progression and metastasis on already established cancers rather than on the prevention of primary cancer occurrence or its cure.

\section{$\beta$-blocker treatment of $\mathrm{IH}$}

$\mathrm{IH}$, which is the most common infancy tumor, is a benign vascular neoplasm resulting from the abnormal proliferation of endothelial cells and angiogenesis. In 2008, LéautéLabrèze et $\mathrm{al}^{47}$ described their serendipitous observation of the anti-proliferative effect of propranolol on severe IHs. The authors described the rapid onset of the effect of propranolol treatment as an IH color change from red to purple within 24 hours, and they also observed a softening of the lesions. After this report, a number of studies further demonstrated that $\beta$-blockers other than propranolol (eg, timolol, acebutolol, and atenolol) were effective at halting hemangioma growth with few adverse side effects. ${ }^{120-124}$ The rapid action of $\beta$-blockers was especially dramatic in cases involving dyspnea, hemodynamic compromise, or palpebral occlusion. Another remarkable aspect of $\beta$-blocker treatment was that not only was the IH growth stabilized but improvement continued until complete involution was achieved, leading to a considerable shortening of the natural course of IH. ${ }^{120}$ This medication may be particularly useful in clinical practice to hasten involution and as a replacement for early surgery or to lower the age at which timely surgery can be performed to maximize excision with minimal scarring.

A randomized, double-blind, placebo-controlled, parallelgroup trial was conducted at a single institution in Australia by Hogeling et al ${ }^{125}$ between June 2009 and December 2010 . Forty children between the ages of 9 weeks and 5 years with cutaneous IH were included in the study. The study medication was dispensed at a ratio of 1:1 (placebo vs propranolol). Outcome measures included the blinded volume estimation, IH color (redness or blueness), and tumor elevation. The study concluded that propranolol users were more likely to show a significant reduction in both tumor volume and redness/elevation. Recently, another blinded cohort study by Pope et al, ${ }^{126}$ explored the efficacy and safety of nadolol, a nonselective $\beta$-blocker with no intrinsic sympathomimetic activity, in patients with IH. A total of 19 patients were included in this study. Ten patients were recruited for the nadolol group, and 9 patients were recruited for the propranolol groups. The authors established that patients who were treated with nadolol had a more favorable response and fewer parental reports of minor adverse events than patients who were treated with propranolol.

\section{Conclusion and future directions}

The findings summarized above demonstrate that $\beta$-blockers have multiple biologic functions for inhibiting tumor progression and metastasis. The results from these preclinical and pharmacoepidemiologic studies support the need for further trials in clinical oncology. Because host factors (eg, adiposity and weight gain, physical activity, and alcohol and tobacco use), ${ }^{115}$ confounding with other pharmacologic exposures (eg, 
angiotensin-converting enzyme inhibitors and aspirin) $)^{115,119}$ and comorbid medical conditions (eg, system inflammation or infectious disease $)^{127}$ can influence survival and recurrence after cancer treatment, further observational studies are not likely to definitively establish the clinical utility of $\beta$-blockers in cancer. Therefore, randomized controlled trials may provide the only way to overcome the selection and ascertainment bias. ${ }^{50}$ Additionally, despite the apparent widespread use of $\beta$-blockers, the current data are limited, and many studies are unable to fully explore the dose-response relationship and the effects of $\beta$-blocker exposure on subgroups of patients due to limited sample sizes. Larger multicenter trials may provide more detailed information regarding the use of $\beta$-blockers in subsets of patients with various tumor types and provide the opportunity to definitively assess the protective effects of $\beta$-blockers on a clinical tumor population. It has also been suggested that nonselective blockers might be preferred over selective $\beta_{1}$-blockers because immunocytes predominantly express $\beta_{2}$-AR over $\beta_{1}-A R$, and both have been implicated in tumor progression. ${ }^{44,55,128}$ In addition, it was reported that the current selective $\beta_{1}$-blockers in use are not entirely $\beta_{1}$-specific. Indeed, all of them partially inhibit $\beta_{2}$-AR. ${ }^{129}$ It is therefore possible that even limited $\beta_{2}$-adrenergic inhibition by $\beta_{1}$-blockers might be sufficient to inhibit tumor progression. ${ }^{130}$ Thus, nonselective blockers such as propranolol and nadolol should be proposed for consideration in future randomized controlled trials.

\section{Acknowledgments}

This work was supported by grants from the National Natural Science Foundation of China (Grants 81071903 and 81072069) (to Li); the Key Clinical Discipline of the Ministry of Health (Grant 201043941) (to Li); and the Mingdao Project of Fudan University (to Ji and Chen). No institution was involved in data interpretation, in writing the article, or in the decision to submit the paper for publication.

\section{Authors' contributions}

YJ and SYC drafted the manuscript. KL, XMX, and SZ revised the manuscript. All of the authors have read and approved the final manuscript.

\section{Disclosure}

The authors report no conflicts of interest in this work.

\section{References}

1. Helfand M, Peterson K, Christensen V, Dana T, Thakurta S. Drug Class Reviews: Beta Adrenergic Blockers: Final Report Update 4 [Internet]. In: Drug Class Reviews. Portland: Oregon Health and Science University; 2009.
2. Foody JM, Farrell MH, Krumholz HM. Beta-blocker therapy in heart failure: scientific review. JAMA. 2002;287(7):883-889.

3. Meijler FL. Sir James Black, FRS, FRCP, FACC: Nobel laureate 1988. J Am Coll Cardiol. 1989;13(3):769-770.

4. Herlenius E, Lagercrantz H. Neurotransmitters and neuromodulators during early human development. Early Hum Dev. 2001;65(1): 21-37.

5. Anitole-Misleh KG, Brown KM. Developmental regulation of catecholamine levels during sea urchin embryo morphogenesis. Comp Biochem Physiol A Mol Integr Physiol. 2004;137(1):39-50.

6. Kim MO, Na SI, Lee MY, Heo JS, Han HJ. Epinephrine increases DNA synthesis via ERK1/2s through cAMP, $\mathrm{Ca}(2+) / \mathrm{PKC}$, and PI3K/ Akt signaling pathways in mouse embryonic stem cells. J Cell Biochem. 2008;104(4):1407-1420.

7. Sloan EK, Priceman SJ, Cox BF, et al. The sympathetic nervous system induces a metastatic switch in primary breast cancer. Cancer Res. 2010;70(18):7042-7052.

8. Hance MW, Dhar MS, Plummer HK 3rd. G-protein inwardly rectifying potassium channel 1 (GIRK1) knockdown decreases beta-adrenergic, MAP kinase and Akt signaling in the MDA-MB-453 breast cancer cell line. Breast Cancer (Auckl). 2008;1:25-34.

9. Al-Wadei HA, Al-Wadei MH, Schuller HM. Cooperative regulation of non-small cell lung carcinoma by nicotinic and beta-adrenergic receptors: a novel target for intervention. PLoS One. 2012;7(1): e29915.

10. Huang XY, Wang HC, Yuan Z, Huang J, Zheng Q. Norepinephrine stimulates pancreatic cancer cell proliferation, migration and invasion via beta-adrenergic receptor-dependent activation of P38/MAPK pathway. Hepatogastroenterology. 2012;59(115): 889-893.

11. Al-Wadei HA, Plummer HK 3rd, Schuller HM. Nicotine stimulates pancreatic cancer xenografts by systemic increase in stress neurotransmitters and suppression of the inhibitory neurotransmitter gammaaminobutyric acid. Carcinogenesis. 2009;30(3):506-511.

12. Zhang D, Ma Q, Wang Z, et al. Beta2-adrenoceptor blockage induces G1/S phase arrest and apoptosis in pancreatic cancer cells via Ras/Akt/ NFkappaB pathway. Mol Cancer. 2011;10:146.

13. Palm D, Lang K, Niggemann B, et al. The norepinephrine-driven metastasis development of PC-3 human prostate cancer cells in BALB/c nude mice is inhibited by beta-blockers. Int J Cancer. 2006; 118(11):2744-2749.

14. Hazut O, Shaashua L, Benish M, et al. The effect of beta-adrenergic blockade and COX-2 inhibition on healing of colon, muscle, and skin in rats undergoing colonic anastomosis. Int J Clin Pharmacol Ther. 2011;49(9):545-554.

15. Shin VY, Jin HC, Ng EK, et al. Nicotine and 4-(methylnitrosamino)1-(3-pyridyl)-1-butanone induce cyclooxygenase-2 activity in human gastric cancer cells: Involvement of nicotinic acetylcholine receptor (nAChR) and beta-adrenergic receptor signaling pathways. Toxicol Appl Pharmacol. 2008;233(2):254-261.

16. Lee JW, Shahzad MM, Lin YG, et al. Surgical stress promotes tumor growth in ovarian carcinoma. Clin Cancer Res. 2009;15(8): 2695-2702.

17. Schuller HM. Is cancer triggered by altered signalling of nicotinic acetylcholine receptors? Nat Rev Cancer. 2009;9(3):195-205.

18. Montminy M. Transcriptional regulation by cyclic AMP. Annu Rev Biochem. 1997;66:807-822.

19. Zhang X, Odom DT, Koo SH, et al. Genome-wide analysis of cAMPresponse element binding protein occupancy, phosphorylation, and target gene activation in human tissues. Proc Natl Acad Sci U S A. 2005;102(12):4459-4464.

20. Luttrell LM, Ferguson SS, Daaka Y, et al. Beta-arrestin-dependent formation of beta2 adrenergic receptor-Src protein kinase complexes. Science. 1999;283(5402):655-661.

21. de Rooij J, Zwartkruis FJ, Verheijen MH, et al. Epac is a Rap1 guaninenucleotide-exchange factor directly activated by cyclic AMP. Nature. 1998;396(6710):474-477. 
22. Zieba BJ, Artamonov MV, Jin L, et al. The cAMP-responsive Rap1 guanine nucleotide exchange factor, Epac, induces smooth muscle relaxation by down-regulation of RhoA activity. J Biol Chem. 2011;286(19):16681-16692.

23. Shahzad MM, Arevalo JM, Armaiz-Pena GN, et al. Stress effects on FosB- and interleukin-8 (IL8)-driven ovarian cancer growth and metastasis. J Biol Chem. 2010;285(46):35462-35470.

24. Bernabe DG, Tamae AC, Biasoli ER, Oliveira SH. Stress hormones increase cell proliferation and regulates interleukin-6 secretion in human oral squamous cell carcinoma cells. Brain Behav Immun. 2011; 25(3):574-583.

25. Cole SW, Arevalo JM, Takahashi R, et al. Computational identification of gene-social environment interaction at the human IL6 locus. Proc Natl Acad Sci U S A. 2010;107(12):5681-5686.

26. Chakroborty D, Sarkar C, Basu B, Dasgupta PS, Basu S. Catecholamines regulate tumor angiogenesis. Cancer Res. 2009;69(9):3727-3730.

27. Thaker PH, Han LY, Kamat AA, et al. Chronic stress promotes tumor growth and angiogenesis in a mouse model of ovarian carcinoma. Nat Med. 2006;12(8):939-944.

28. Entschladen F, Drell TT, Lang K, Joseph J, Zaenker KS. Tumour-cell migration, invasion, and metastasis: navigation by neurotransmitters. Lancet Oncol. 2004;5(4):254-258

29. Sood AK, Bhatty R, Kamat AA, et al. Stress hormone-mediated invasion of ovarian cancer cells. Clin Cancer Res. 2006;12(2):369-375.

30. Jin Z, Gao F, Flagg T, Deng X. Nicotine induces multi-site phosphorylation of Bad in association with suppression of apoptosis. J Biol Chem. 2004;279(22):23837-23844.

31. Sood AK, Armaiz-Pena GN, Halder J, et al. Adrenergic modulation of focal adhesion kinase protects human ovarian cancer cells from anoikis. J Clin Invest. 2010;120(5):1515-1523.

32. Hara MR, Kovacs JJ, Whalen EJ, et al. A stress response pathway regulates DNA damage through beta2-adrenoreceptors and beta-arrestin-1. Nature. 2011;477(7364):349-353.

33. Sacharczuk M, Jaszczak K, Sadowski B. Chromosomal NOR activity in mice selected for high and low swim stress-induced analgesia. Behav Genet. 2003;33(4):435-441.

34. Glaser R, Kiecolt-Glaser JK. Stress-induced immune dysfunction: implications for health. Nat Rev Immunol. 2005;5(3):243-251.

35. Antoni MH, Lutgendorf SK, Cole SW, et al. The influence of biobehavioural factors on tumour biology: pathways and mechanisms. Nat Rev Cancer. 2006;6(3):240-248.

36. Goldfarb Y, Sorski L, Benish M, Levi B, Melamed R, Ben-Eliyahu S. Improving postoperative immune status and resistance to cancer metastasis: a combined perioperative approach of immunostimulation and prevention of excessive surgical stress responses. Ann Surg. 2011;253(4):798-810.

37. Glasner A, Avraham R, Rosenne E, et al. Improving survival rates in two models of spontaneous postoperative metastasis in mice by combined administration of a beta-adrenergic antagonist and a cyclooxygenase-2 inhibitor. J Immunol. 2010;184(5):2449-2457.

38. Greenberger S, Boscolo E, Adini I, Mulliken JB, Bischoff J. Corticosteroid suppression of VEGF-A in infantile hemangiomaderived stem cells. N Engl J Med. 2010;362(11):1005-1013.

39. Asahara T, Takahashi T, Masuda H, et al. VEGF contributes to postnatal neovascularization by mobilizing bone marrow-derived endothelial progenitor cells. EMBO J. 1999;18(14):3964-3972.

40. Kwak C, Jin RJ, Lee C, Park MS, Lee SE. Thrombospondin-1, vascular endothelial growth factor expression and their relationship with p53 status in prostate cancer and benign prostatic hyperplasia. BJU Int. 2002;89(3):303-309.

41. Toi M, Inada K, Suzuki H, Tominaga T. Tumor angiogenesis in breast cancer: its importance as a prognostic indicator and the association with vascular endothelial growth factor expression. Breast Cancer Res Treat. 1995;36(2):193-204.

42. El-Assal ON, Yamanoi A, Soda Y, et al. Clinical significance of microvessel density and vascular endothelial growth factor expression in hepatocellular carcinoma and surrounding liver: possible involvement of vascular endothelial growth factor in the angiogenesis of cirrhotic liver. Hepatology. 1998;27(6):1554-1562.
43. Zhang L, Lin X, Wang W, et al. Circulating level of vascular endothelial growth factor in differentiating hemangioma from vascular malformation patients. Plast Reconstr Surg. 2005;116(1):200-204.

44. Park SY, Kang JH, Jeong KJ, et al. Norepinephrine induces VEGF expression and angiogenesis by a hypoxia-inducible factor-1alpha protein-dependent mechanism. Int $J$ Cancer. 2011;128(10): 2306-2316.

45. Iaccarino G, Ciccarelli M, Sorriento D, et al. Ischemic neoangiogenesis enhanced by beta2-adrenergic receptor overexpression: a novel role for the endothelial adrenergic system. Circ Res. 2005;97(11):1182-1189.

46. Ciccarelli M, Sorriento D, Cipolletta E, et al. Impaired neoangiogenesis in beta(2)-adrenoceptor gene-deficient mice: restoration by intravascular human beta(2)-adrenoceptor gene transfer and role of NFkappaB and CREB transcription factors. Br J Pharmacol. 2011;162(3):712-721.

47. Léauté-Labrèze C, Dumas DLRE, Hubiche T, Boralevi F, Thambo JB, Taieb A. Propranolol for severe hemangiomas of infancy. $N$ Engl J Med. 2008;358(24):2649-2651.

48. Storch $\mathrm{CH}$, Hoeger $\mathrm{PH}$. Propranolol for infantile haemangiomas: insights into the molecular mechanisms of action. Br J Dermatol. 2010; 163(2):269-274

49. Chim H, Armijo BS, Miller E, Gliniak C, Serret MA, Gosain AK. Propranolol induces regression of hemangioma cells through HIF-1alphamediated inhibition of VEGF-A. Ann Surg. 2012;256(1):146-156.

50. Cole SW, Sood AK. Molecular pathways: beta-adrenergic signaling in cancer. Clin Cancer Res. 2012;18(5):1201-1206.

51. Schuller HM. Beta-adrenergic signaling, a novel target for cancer therapy? Oncotarget. 2010;1(7):466-469.

52. Schuller HM, Cole B. Regulation of cell proliferation by beta-adrenergic receptors in a human lung adenocarcinoma cell line. Carcinogenesis. 1989;10(9):1753-1755

53. Al-Wadei HA, Takahashi T, Schuller HM. Caffeine stimulates the proliferation of human lung adenocarcinoma cells and small airway epithelial cells via activation of PKA, CREB and ERK1/2. Oncol Rep. 2006;15(2):431-435.

54. Al-Wadei HA, Ullah MF, Al-Wadei MH. Intercepting neoplastic progression in lung malignancies via the beta adrenergic (beta-AR) pathway: implications for anti-cancer drug targets. Pharmacol Res. 2012;66(1):33-40.

55. Liu X, Wu WK, Yu L, et al. Epinephrine stimulates esophageal squamous-cell carcinoma cell proliferation via beta-adrenoceptor-dependent transactivation of extracellular signal-regulated kinase/cyclooxygenase-2 pathway. J Cell Biochem. 2008;105(1): 53-60.

56. Slotkin TA, Zhang J, Dancel R, Garcia SJ, Willis C, Seidler FJ. Betaadrenoceptor signaling and its control of cell replication in MDA-MB231 human breast cancer cells. Breast Cancer Res Treat. 2000;60(2) 153-166.

57. Carie AE, Sebti SM. A chemical biology approach identifies a beta-2 adrenergic receptor agonist that causes human tumor regression by blocking the Raf-1/Mek-1/Erk1/2 pathway. Oncogene. 2007;26(26): 3777-3788

58. Schuller HM, Tithof PK, Williams M, Plummer HR. The tobaccospecific carcinogen 4-(methylnitrosamino)-1-(3-pyridyl)-1-butanone is a beta-adrenergic agonist and stimulates DNA synthesis in lung adenocarcinoma via beta-adrenergic receptor-mediated release of arachidonic acid. Cancer Res. 1999;59(18):4510-4515.

59. Schuller HM, Orloff M. Tobacco-specific carcinogenic nitrosamines. Ligands for nicotinic acetylcholine receptors in human lung cancer cells. Biochem Pharmacol. 1998;55(9):1377-1384.

60. Schuller HM, Witschi HP, Nylen E, Joshi PA, Correa E, Becker KL. Pathobiology of lung tumors induced in hamsters by 4-(methylnitrosamino)-1-(3-pyridyl)-1-butanone and the modulating effect of hyperoxia. Cancer Res. 1990;50(6):1960-1965.

61. Laag E, Majidi M, Cekanova M, Masi T, Takahashi T, Schuller HM. NNK activates ERK1/2 and CREB/ATF-1 via beta-1-AR and EGFR signaling in human lung adenocarcinoma and small airway epithelial cells. Int J Cancer. 2006;119(7):1547-1552. 
62. Majidi M, Al-Wadei HA, Takahashi T, Schuller HM. Nongenomic beta estrogen receptors enhance beta1 adrenergic signaling induced by the nicotine-derived carcinogen 4-(methylnitrosamino)-1-(3-pyridyl)1-butanone in human small airway epithelial cells. Cancer Res. 2007;67(14):6863-6871.

63. Wong HP, Yu L, Lam EK, Tai EK, Wu WK, Cho CH. Nicotine promotes colon tumor growth and angiogenesis through beta-adrenergic activation. Toxicol Sci. 2007;97(2):279-287.

64. Wong HP, Yu L, Lam EK, Tai EK, Wu WK, Cho CH. Nicotine promotes cell proliferation via alpha7-nicotinic acetylcholine receptor and catecholamine-synthesizing enzymes-mediated pathway in human colon adenocarcinoma HT-29 cells. Toxicol Appl Pharmacol. 2007;221(3):261-267.

65. Pierce KL, Premont RT, Lefkowitz RJ. Seven-transmembrane receptors. Nat Rev Mol Cell Biol. 2002;3(9):639-650.

66. JiY, Li K, Xiao X, Zheng S, Xu T, Chen S. Effects of propranolol on the proliferation and apoptosis of hemangioma-derived endothelial cells. $J$ Pediatr Surg. In press 2012.

67. Sastry KS, Karpova Y, Prokopovich S, et al. Epinephrine protects cancer cells from apoptosis via activation of cAMP-dependent protein kinase and BAD phosphorylation. J Biol Chem. 2007;282(19):14094-14100.

68. Zhang D, Ma Q, Shen S, Hu H. Inhibition of pancreatic cancer cell proliferation by propranolol occurs through apoptosis induction: the study of beta-adrenoceptor antagonist's anticancer effect in pancreatic cancer cell. Pancreas. 2009;38(1):94-100.

69. Shan T, Ma Q, Zhang D, et al. Beta2-adrenoceptor blocker synergizes with gemcitabine to inhibit the proliferation of pancreatic cancer cells via apoptosis induction. Eur J Pharmacol. 2011;665(1-3):1-7.

70. Liao X, Che X, Zhao W, Zhang D, Bi T, Wang G. The beta-adrenoceptor antagonist, propranolol, induces human gastric cancer cell apoptosis and cell cycle arrest via inhibiting nuclear factor kappaB signaling. Oncol Rep. 2010;24(6):1669-1676.

71. Yawata A, Adachi M, Okuda H, et al. Prolonged cell survival enhances peritoneal dissemination of gastric cancer cells. Oncogene. 1998;16(20):2681-2686.

72. Sood AK, Armaiz-Pena GN, Halder J, et al. Adrenergic modulation of focal adhesion kinase protects human ovarian cancer cells from anoikis. J Clin Invest. 2010;120(5):1515-1523.

73. Marx J. Cancer research. Inflammation and cancer: the link grows stronger. Science. 2004;306(5698):966-968.

74. Xie G, Yao Q, Liu Y, et al. IL-6-induced epithelial-mesenchymal transition promotes the generation of breast cancer stem-like cells analogous to mammosphere cultures. Int J Oncol. 2012;40(4):1171-1179.

75. Obata NH, Tamakoshi K, Shibata K, Kikkawa F, Tomoda Y. Effects of interleukin- 6 on in vitro cell attachment, migration and invasion of human ovarian carcinoma. Anticancer Res. 1997;17(1A):337-342.

76. Heikkila K, Ebrahim S, Lawlor DA. Systematic review of the association between circulating interleukin-6 (IL-6) and cancer. Eur J Cancer. 2008;44(7):937-945.

77. Scambia G, Testa U, Panici PB, et al. Interleukin- 6 serum levels in patients with gynecological tumors. Int J Cancer. 1994;57(3):318-323.

78. Rohrbach S, Engelhardt S, Lohse MJ, Werdan K, Holtz J, Muller-Werdan U. Activation of AP-1 contributes to the betaadrenoceptor-mediated myocardial induction of interleukin-6. Mol Med. 2007;13(11-12):605-614.

79. Yang EV, Kim SJ, Donovan EL, et al. Norepinephrine upregulates VEGF, IL-8, and IL-6 expression in human melanoma tumor cell lines: implications for stress-related enhancement of tumor progression. Brain Behav Immun. 2009;23(2):267-275.

80. Tan KS, Nackley AG, Satterfield K, Maixner W, Diatchenko L, Flood PM. Beta2 adrenergic receptor activation stimulates proinflammatory cytokine production in macrophages via PKA- and NFkappaB-independent mechanisms. Cell Signal. 2007;19(2):251-260.

81. Nilsson MB, Armaiz-Pena G, Takahashi R, et al. Stress hormones regulate interleukin-6 expression by human ovarian carcinoma cells through a Src-dependent mechanism. J Biol Chem. 2007;282(41): 29919-29926.
82. Madden KS, Szpunar MJ, Brown EB. Beta-adrenergic receptors (betaAR) regulate VEGF and IL-6 production by divergent pathways in high beta-AR-expressing breast cancer cell lines. Breast Cancer Res Treat. 2011;130(3):747-758.

83. Koch AE, Polverini PJ, Kunkel SL, et al. Interleukin-8 as a macrophage-derived mediator of angiogenesis. Science. 1992;258(5089): 1798-1801.

84. Kassim SK, El-Salahy EM, Fayed ST, et al. Vascular endothelial growth factor and interleukin-8 are associated with poor prognosis in epithelial ovarian cancer patients. Clin Biochem. 2004;37(5):363-369.

85. Schreiber RD, Old LJ, Smyth MJ. Cancer immunoediting: integrating immunity's roles in cancer suppression and promotion. Science. 2011;331(6024):1565-1570.

86. Goldfarb Y, Sorski L, Benish M, Levi B, Melamed R, Ben-Eliyahu S. Improving postoperative immune status and resistance to cancer metastasis: a combined perioperative approach of immunostimulation and prevention of excessive surgical stress responses. Ann Surg. 2011;253(4):798-810.

87. McGregor BA, Antoni MH, Boyers A, Alferi SM, Blomberg BB, Carver CS. Cognitive-behavioral stress management increases benefit finding and immune function among women with early-stage breast cancer. J Psychosom Res. 2004;56(1):1-8.

88. Andersen BL, Farrar WB, Golden-Kreutz DM, et al. Psychological, behavioral, and immune changes after a psychological intervention: a clinical trial. J Clin Oncol. 2004;22(17):3570-3580.

89. Cunnick JE, Lysle DT, Kucinski BJ, Rabin BS. Evidence that shockinduced immune suppression is mediated by adrenal hormones and peripheral beta-adrenergic receptors. Pharmacol Biochem Behav. 1990;36(3):645-651.

90. Pollard JW. Tumour-educated macrophages promote tumour progression and metastasis. Nat Rev Cancer. 2004;4(1):71-78.

91. Masur K, Niggemann B, Zanker KS, Entschladen F. Norepinephrineinduced migration of SW 480 colon carcinoma cells is inhibited by beta-blockers. Cancer Res. 2001;61(7):2866-2869.

92. Lang K, Drell TT, Lindecke A, et al. Induction of a metastatogenic tumor cell type by neurotransmitters and its pharmacological inhibition by established drugs. Int J Cancer. 2004;112(2):231-238.

93. Drell TT, Joseph J, Lang K, Niggemann B, Zaenker KS, Entschladen F. Effects of neurotransmitters on the chemokinesis and chemotaxis of MDA-MB-468 human breast carcinoma cells. Breast Cancer Res Treat. 2003;80(1):63-70.

94. Joseph J, Niggemann B, Zaenker KS, Entschladen F. The neurotransmitter gamma-aminobutyric acid is an inhibitory regulator for the migration of SW 480 colon carcinoma cells. Cancer Res. 2002;62(22): $6467-6469$.

95. Yang EV, Bane CM, MacCallum RC, Kiecolt-Glaser JK, Malarkey WB, Glaser R. Stress-related modulation of matrix metalloproteinase expression. J Neuroimmunol. 2002;133(1-2):144-150.

96. Entschladen F, Drell TT, Lang K, Joseph J, Zaenker KS. Tumour-cell migration, invasion, and metastasis: navigation by neurotransmitters. Lancet Oncol. 2004;5(4):254-258.

97. Lutgendorf SK, Lamkin DM, Jennings NB, et al. Biobehavioral influences on matrix metalloproteinase expression in ovarian carcinoma. Clin Cancer Res. 2008;14(21):6839-6846.

98. Landen CJ, Lin YG, Armaiz PG, et al. Neuroendocrine modulation of signal transducer and activator of transcription-3 in ovarian cancer. Cancer Res. 2007;67(21):10389-10396.

99. Yang EV, Sood AK, Chen M, et al. Norepinephrine up-regulates the expression of vascular endothelial growth factor, matrix metalloproteinase (MMP)-2, and MMP-9 in nasopharyngeal carcinoma tumor cells. Cancer Res. 2006;66(21):10357-10364.

100. Guo K, Ma Q, Wang L, et al. Norepinephrine-induced invasion by pancreatic cancer cells is inhibited by propranolol. Oncol Rep. 2009;22(4):825-830.

101. Schuller HM, Al-Wadei HA, Ullah MF, Plummer HR. Regulation of pancreatic cancer by neuropsychological stress responses: a novel target for intervention. Carcinogenesis. 2012;33(1):191-196. 
102. Al-Wadei HA, Plummer HR, Ullah MF, Unger B, Brody JR, Schuller HM. Social stress promotes and gamma-aminobutyric acid inhibits tumor growth in mouse models of non-small cell lung cancer. Cancer Prev Res (Phila). 2012;5(2):189-196.

103. Powe DG, Entschladen F. Targeted therapies: Using beta-blockers to inhibit breast cancer progression. Nat Rev Clin Oncol. 2011;8(9): $511-512$.

104. [No authors listed]. Medical Research Council trial of treatment of hypertension in older adults: principal results. MRC Working Party. BMJ. 1992;304(6824):405-412.

105. Jick H. Calcium-channel blockers and risk of cancer. Lancet. 1997; 349(9066):1699-1700.

106. Algazi M, Plu-Bureau G, Flahault A, Dondon M, Le MG. Is betablocker treatment associated with a decrease in the risk of cancer. Lett Drug Des Discov. 2006;9(3):653-661.

107. Perron L, Bairati I, Harel F, Meyer F. Antihypertensive drug use and the risk of prostate cancer (Canada). Cancer Causes Control. 2004; 15(6):535-541

108. Fitzpatrick AL, Daling JR, Furberg CD, Kronmal RA, Weissfeld JL. Hypertension, heart rate, use of antihypertensives, and incident prostate cancer. Ann Epidemiol. 2011;11(8):534-542.

109. Assimes TL, Elstein E, Langleben A, Suissa S. Long-term use of antihypertensive drugs and risk of cancer. Pharmacoepidemiol Drug Saf. 2008;17(11):1039-1049.

110. Grossman E, Messerli FH, Goldbourt U. Antihypertensive therapy and the risk of malignancies. Eur Heart J. 2001;22(15):1343-1352.

111. Jansen L, Below J, Chang-Claude J, Brenner H, Hoffmeister M. Beta blocker use and colorectal cancer risk: population-based case-control study. Cancer. 2012;118(16):3911-3919.

112. Rodriguez C, Jacobs EJ, Deka A, et al. Use of blood-pressure-lowering medication and risk of prostate cancer in the Cancer Prevention Study II Nutrition Cohort. Cancer Causes Control. 2009;20(5):671-679.

113. De Giorgi V, Grazzini M, Gandini S, et al. Treatment with beta-blockers and reduced disease progression in patients with thick melanoma. Arch Intern Med. 2011;171(8):779-781.

114. Lemeshow S, Sorensen HT, Phillips G, et al. Beta-blockers and survival among Danish patients with malignant melanoma: a populationbased cohort study. Cancer Epidemiol Biomarkers Prev. 2011;20(10): 2273-2279.

115. Barron TI, Connolly RM, Sharp L, Bennett K, Visvanathan K. Beta blockers and breast cancer mortality: a population- based study. J Clin Oncol. 2011;29(19):2635-2644.

116. Melhem-Bertrandt A, Chavez-Macgregor M, Lei X, et al. Betablocker use is associated with improved relapse-free survival in patients with triple-negative breast cancer. J Clin Oncol. 2011;29(19): 2645-2652.

117. Bangalore S, Kumar S, Kjeldsen SE, et al. Antihypertensive drugs and risk of cancer: network meta-analyses and trial sequential analyses of 324,168 participants from randomised trials. Lancet Oncol. 2011; 12(1):65-82.
118. Powe DG, Voss MJ, Zanker KS, et al. Beta-blocker drug therapy reduces secondary cancer formation in breast cancer and improves cancer specific survival. Oncotarget. 2010;1(7):628-638.

119. Ganz PA, Habel LA, Weltzien EK, Caan BJ, Cole SW. Examining the influence of beta blockers and ACE inhibitors on the risk for breast cancer recurrence: results from the LACE cohort. Breast Cancer Res Treat. 2011;129(2):549-556.

120. Sans V, de la Roque ED, Berge J, et al. Propranolol for severe infantile hemangiomas: follow-up report. Pediatrics. 2009;124(3): e423-e431.

121. Bigorre M, Van Kien AK, Valette H. Beta-blocking agent for treatment of infantile hemangioma. Plast Reconstr Surg. 2009;123(6): $195 \mathrm{e}-196 \mathrm{e}$.

122. Leboulanger N, Fayoux P, Teissier N, et al. Propranolol in the therapeutic strategy of infantile laryngotracheal hemangioma: A preliminary retrospective study of French experience. Int $J$ Pediatr Otorhinolaryngol. 2010;74(11):1254-1257.

123. Raphael MF, de Graaf M, Breugem CC, Pasmans SG, Breur JM. Atenolol: a promising alternative to propranolol for the treatment of hemangiomas. J Am Acad Dermatol. 2011;65(2):420-421.

124. Chakkittakandiyil A, Phillips R, Frieden IJ, et al. Timolol maleate $0.5 \%$ or $0.1 \%$ gel-forming solution for infantile hemangiomas: a retrospective, multicenter, cohort study. Pediatr Dermatol. 2012; 29(1):28-31.

125. Hogeling M, Adams S, Wargon O. A randomized controlled trial of propranolol for infantile hemangiomas. Pediatrics. 2011;128(2): e259-e266.

126. Pope E, Chakkittakandiyil A, Lara-Corrales I, Maki E, Weinstein M Expanding the therapeutic repertoire of infantile hemangiomas: Cohort blinded study of oral nadolol compared with propranolol. Br J Dermatol. 2012.

127. Pierce BL, Ballard-Barbash R, Bernstein L, et al. Elevated biomarkers of inflammation are associated with reduced survival among breast cancer patients. J Clin Oncol. 2009;27(21):3437-3444.

128. Ben-Eliyahu S, Shakhar G, Page GG, Stefanski V, Shakhar K. Suppression of NK cell activity and of resistance to metastasis by stress: a role for adrenal catecholamines and beta-adrenoceptors. Neuroimmunomodulation. 2000;8(3):154-164.

129. Smith C, Teitler M. Beta-blocker selectivity at cloned human beta 1and beta 2-adrenergic receptors. Cardiovasc Drugs Ther. 1999;13(2): $123-126$.

130. Ganz PA, Cole SW. Expanding our therapeutic options: beta blockers for breast cancer? J Clin Oncol. 2011;29(19):2612-2616.
OncoTargets and Therapy

\section{Publish your work in this journal}

OncoTargets and Therapy is an international, peer-reviewed, open access journal focusing on the pathological basis of all cancers, potential targets for therapy and treatment protocols employed to improve the management of cancer patients. The journal also focuses on the impact of management programs and new therapeutic agents and protocols on

\section{Dovepress}

patient perspectives such as quality of life, adherence and satisfaction The manuscript management system is completely online and includes a very quick and fair peer-review system, which is all easy to use. Visit http://www.dovepress.com/testimonials.php to read real quotes from published authors. 